\title{
Soil erosion, reservoir lake infill and coastal erosion in the Mediterranean coast of southern Spain.
}

\author{
José Luis del Río ${ }^{1}$ Fatima Navas ${ }^{2}$, and Gonzalo Malvarez ${ }^{2}$ \\ ${ }^{1}$ Regional Government of Andalucia Department of Agriculture Fishing and Sustainable \\ Development \\ ${ }^{2}$ Universidad Pablo de Olavide
}

October 31, 2021

\begin{abstract}
The combination of vigorous terrain and millenary human action has produced major changes in vegetation cover, impacting soil losses from slopes and, consequently, sediment production. Increasing focus in the management of water resources led to the widespread construction of dams to generate water flows for iron production, irrigation and to satisfy the increasing demand of the massive urban development along the Costa del Sol. To investigate the connection between soil degradation and loss and river sediment transport retention at a major dam, a first-order sediment yield prediction was established by using a GIS-based model at river basin scale. A quantitative validation of model results is provided by empirical measurements of sedimentation in the main reservoir lake of La Concepción using D_GPS/Echo sounder combination and a Remotely Piloted Aircraft compared with pre-construction blue print topography aimed at documenting spot heights where sediments accumulated or eroded over 50 years. The significant erodibility that we have estimated seems matched by potentially high sediment accumulation rates along selected profiles and spot heights across the bottom of the reservoir lake. Our study discusses that Mediterranean coastal systems may no longer stay in the resilience envelope set by a critically delicate sediment transport balance and without engineering support in the form of direct sediment feeding to the marine system by the permanent nourishment works required. Due to soil loss, sediment entrapment in reservoirs and water management policies, the coastal protection offered by the natural resilience of the beach and dune system is no longer recoverable.
\end{abstract}

\section{Hosted file}

Del Rio, Navas \& Malvarez. Soil erosion, reservoir lake infill and coastal erosion in the Med coast of available at https://authorea.com/users/443810/articles/543718-soil-erosion-reservoir-lakeinfill-and-coastal-erosion-in-the-mediterranean-coast-of-southern-spain 

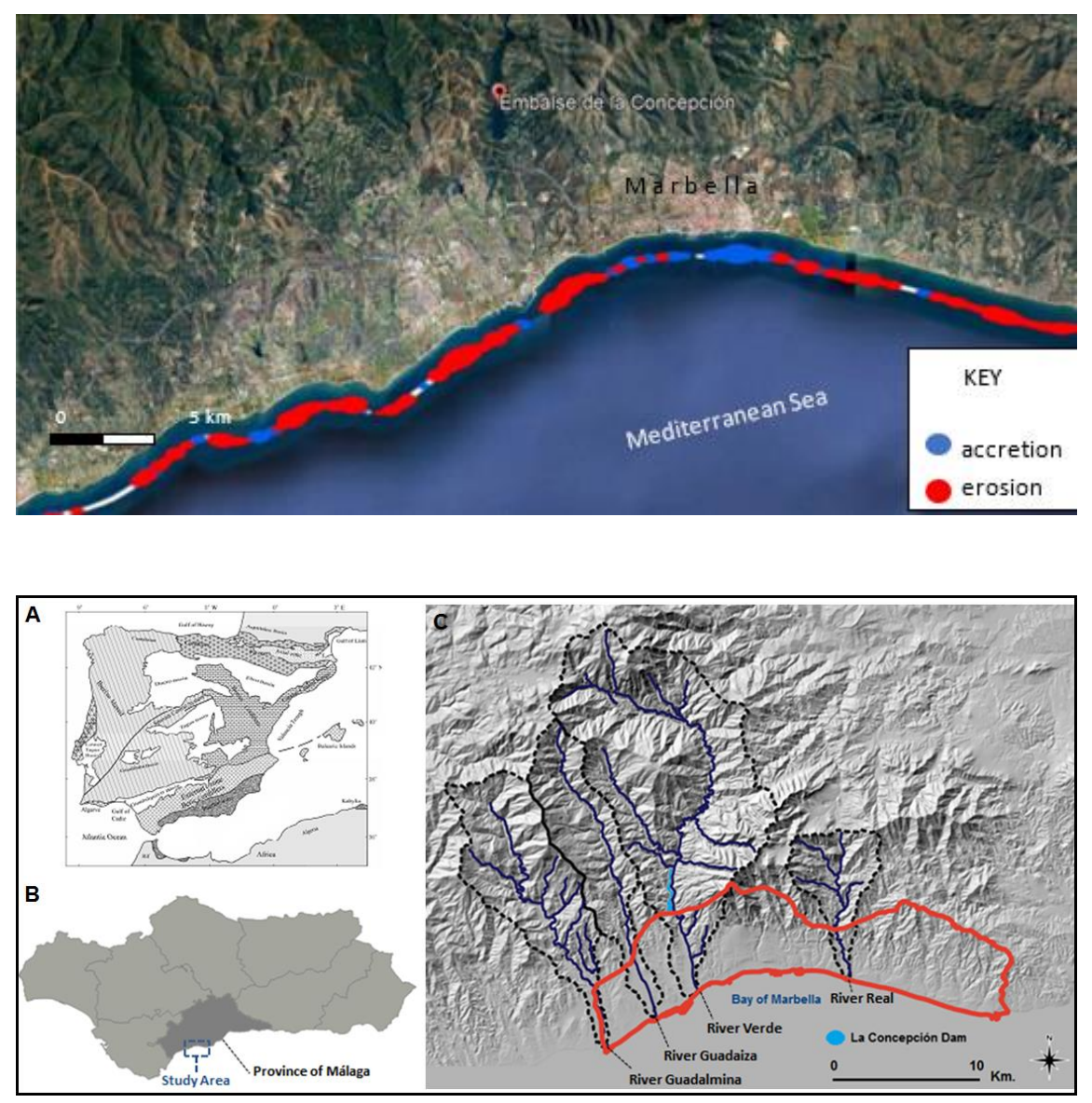


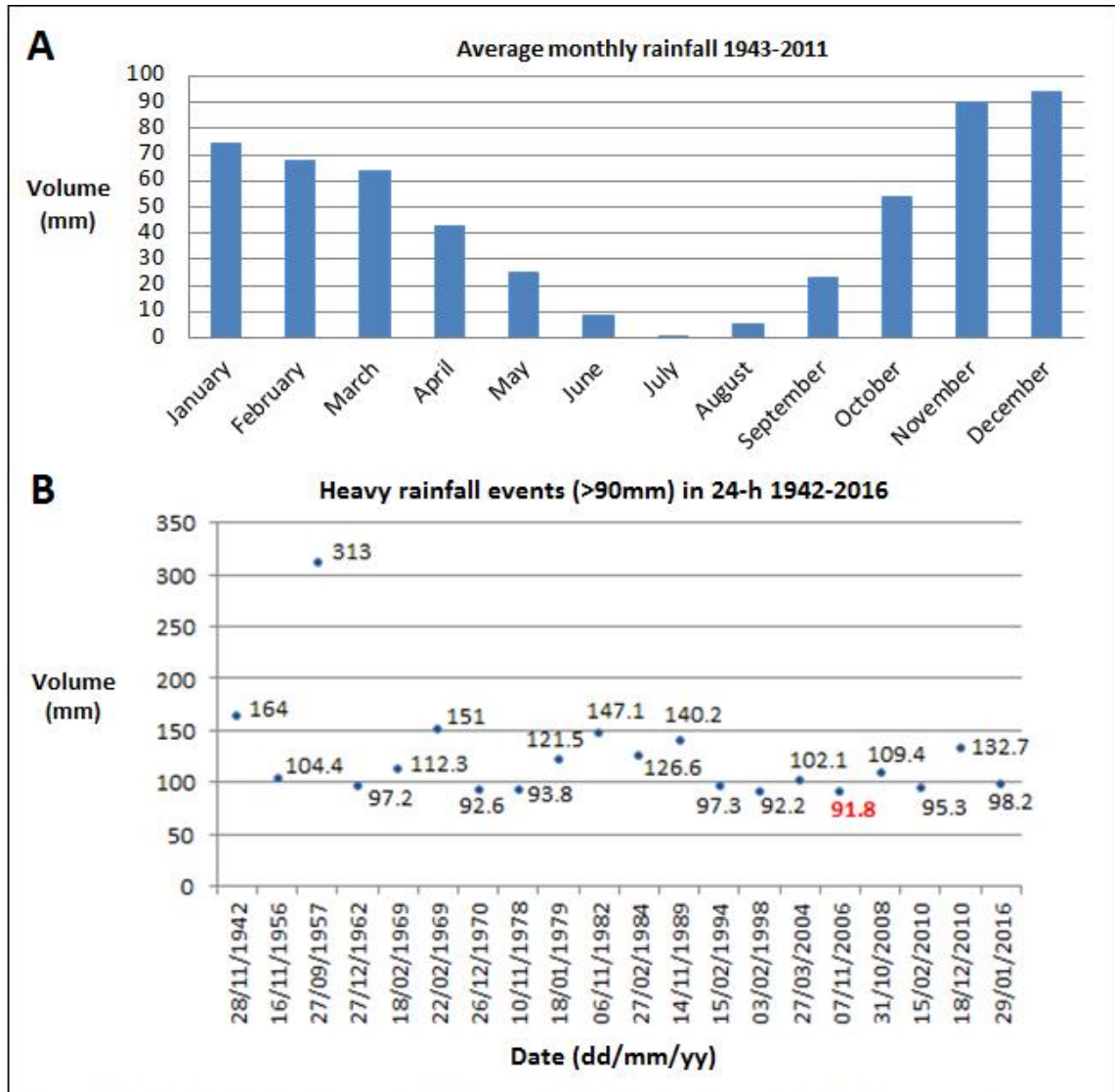

*The unit ' $\mathrm{mm}$ ' on the $\mathrm{Y}$-axis of figures $\mathrm{A}$ and $\mathrm{B}$ means 'millimeters' and is equivalent to litres per meter square.

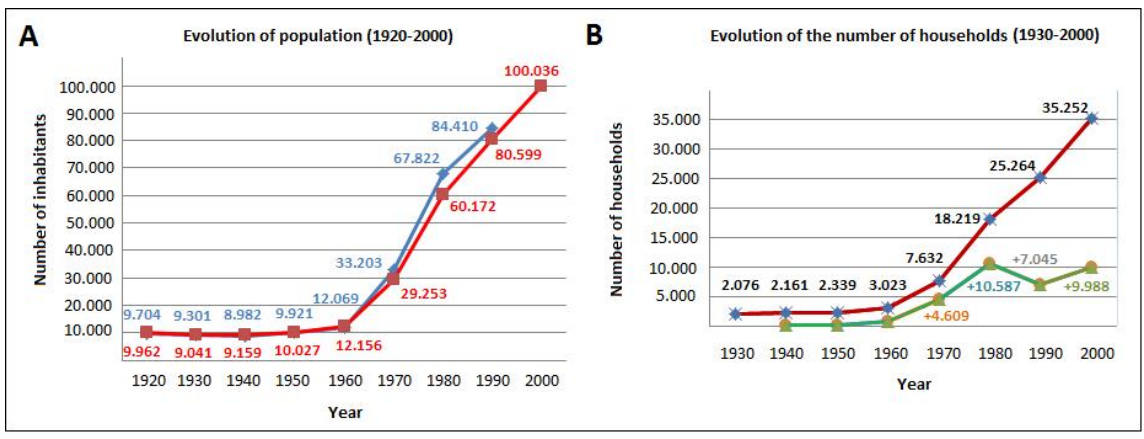



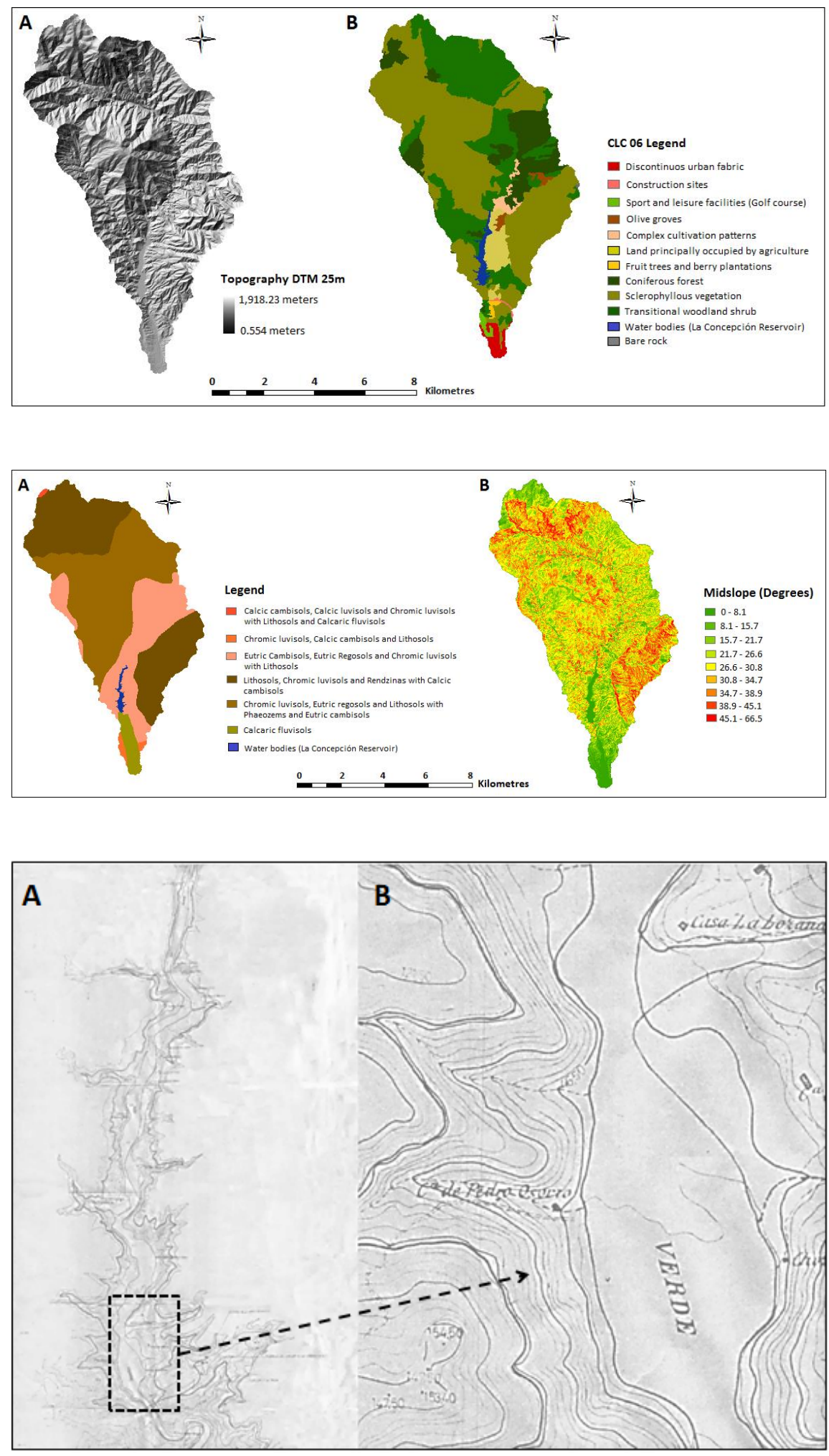

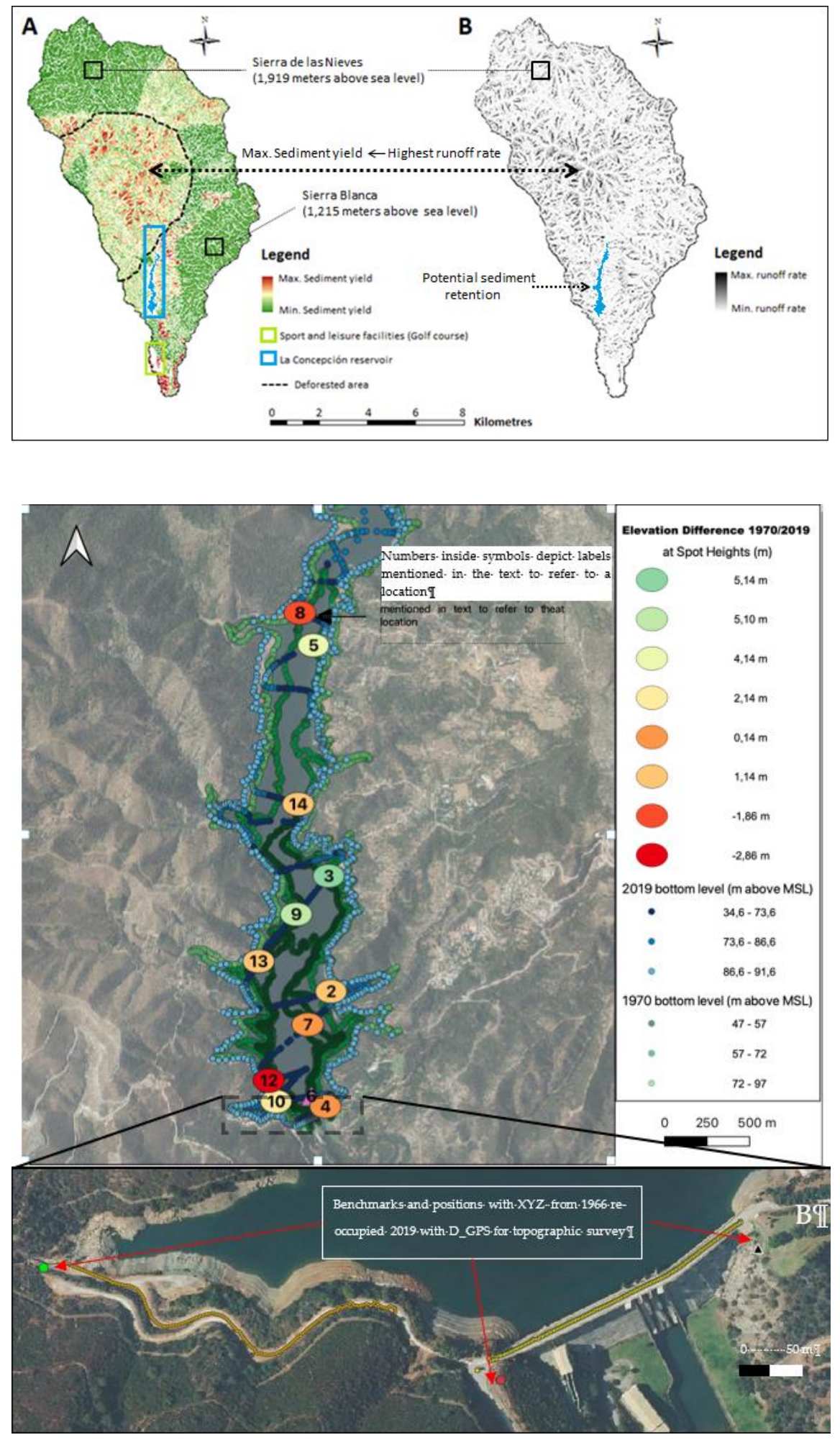